\title{
Primary pulmonary meningioma mimicking lung metastatic tumor: a case report
}

\author{
Ji-Zhuang Luo ${ }^{1 \dagger}$, Cheng Zhan ${ }^{1+}$, Xiang $\mathrm{Ni}^{2}$, Yu Shi ${ }^{1 *}$ (D) and Qun Wang ${ }^{1}$
}

\begin{abstract}
Background: Primary pulmonary meningioma (PPM) is an extremely rare benign tumor. Previous reports indicated that CT features of PPM are single, solid, well-demarcated, homogeneous mass. In this study, we report a case of PPM with atypical CT features.

Case presentation: A 65-year-old female presents to clinic with 1-week acute upper respiratory tract infection. Her chest CT scan revealed a 25-29 mm, round-like, heterogeneous lobulated solitary pulmonary nodule in the right lower lobe. Based on the microscopic features and a wide range of immunohistochemical examinations including vimentine, progesterone receptor (PR), CD34 and S100, the mass was diagnosed as PPM after surgery.
\end{abstract}

Conclusion: PPM is a rare disease, CT features of PPM could be heterogeneous and lobulated. Expression of vimentine, PR, CD34 and S100 helps to diagnosis of PPM.

Keywords: Primary pulmonary meningioma, PPM, Progesterone receptor

\section{Background}

Primary pulmonary meningioma is an extremely rare tumor with uncertain origin. Most PPMs are asymptomatic, grow slowly, and present a benign biological behavior [1]. Histologically, the tumor cells usually show whorls of spindle cells interspersed with abundant psammoma bodies, and positive for vimentin, and EMA (epithelial membrane antigen) [2]. The typical CT features of PPM are single, solid, well-demarcated, homogeneous mass, which was difficult to distinguish with several benign and malignant lung tumors. We report here a 65-year-old female PPM patient with relatively atypical $\mathrm{CT}$ findings. We also performed a wide range of IHC examinations for differential diagnosis.

\section{Case presentation}

A 65-year-old female presents to clinic with 1 week cough. She denies fever, dyspnea, chest pain or constitutional symptoms. She had a history of type II diabetes but with an inadequate controlled serum glucose level for 10 years. Her neutrophils, C-reaction protein (CRP),

\footnotetext{
* Correspondence: shiyuzsyy@163.com

†ji-Zhuang Luo and Cheng Zhan contributed equally to this work.

${ }^{1}$ Department of Thoracic Surgery, Zhongshan Hospital, Fudan University,

Shanghai 200032, People's Republic of China

Full list of author information is available at the end of the article
}

procalcitonin and tumor markers such as carcinoembryonic antigen (CEA), neuron-specific enolase (NSE), squamous cell carcinoma antigen (SCC) were all in normal range. Her T-SPOT.TB assay examination were negative. A CT scan of her chest reveals a $25-29 \mathrm{~mm}$, round-like, heterogeneous lobulated solitary pulmonary nodule without showing any cavity lesions or calcification, in the peripheral right lower lobe. No obvious enlarged hilar or mediastinal lymph nodes were observed (Fig. 1). Preoperative brain magnetic resonance imaging (MRI) scans showed negative findings. The patient hadn't received PET/CT scan for economic reasons.

The patient received lobectomy of right lower lobe and systemic mediastinal lymph nodes dissection. A gross examination revealed a $3.5 \times 2 \times 1.5 \mathrm{~cm}$, well-demarcated, white-pan solid mass. Microscopically, the tumor was composed of spindle cells with a whorl pattern. No atypical cells and mitotic figures were observed (Fig. 2a and b). Immunohistochemically, the tumor cells were positive for vimentine, EMA, PR (progesterone recepters), CD34, D240, S100 (focal) and 2\% tumor cells positive for Ki-67 (Fig. $2 \mathrm{c}-\mathrm{f}$ ). The tumor cells were negative for synaptophysin, SMA (smooth muscle actin), TTF-1 (thyroid transcription factor-1), Chromogranin A, desmin, GFAP, WT-1 (Wilm's tumor gene-1), HBME-1 (Hector Battifora mesothelial

(C) The Author(s). 2018 Open Access This article is distributed under the terms of the Creative Commons Attribution 4.0 International License (http://creativecommons.org/licenses/by/4.0/), which permits unrestricted use, distribution, and reproduction in any medium, provided you give appropriate credit to the original author(s) and the source, provide a link to the Creative Commons license, and indicate if changes were made. The Creative Commons Public Domain Dedication waiver (http://creativecommons.org/publicdomain/zero/1.0/) applies to the data made available in this article, unless otherwise stated. 

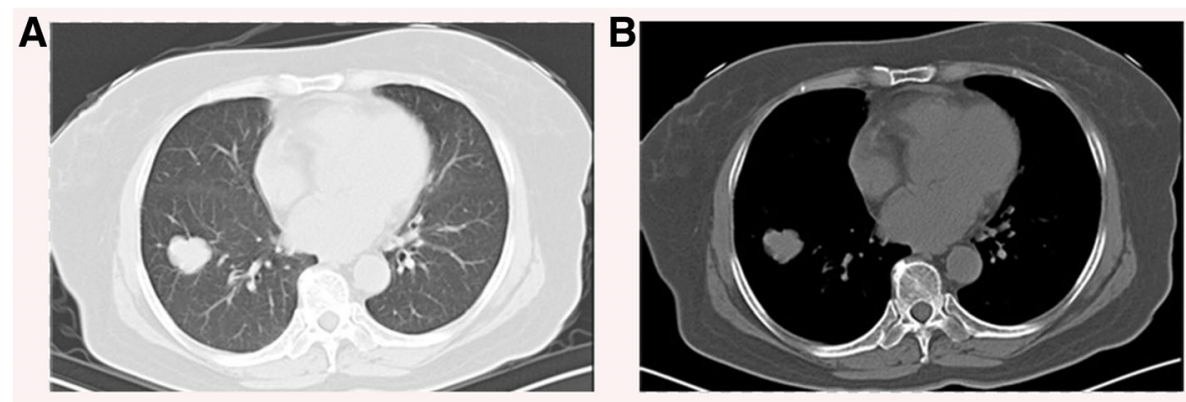

Fig. 1 Chest CT scan showing a nodule in the right lower lung field. a Lung window. b Mediastinal window

epitope-1). Based on the above findings, the tumor was diagnosed as primary pulmonary meningioma (PPM).

\section{Discussion}

Primary pulmonary meningioma is an extremely uncommon lung neoplasm which was first described in 1981 by Erlandson. To date, no more than 50 cases have been reported in the English literature. The origin of PPMs remains uncertain, intrathoracic differentiation of meningocytes, ectopic embryonic remnants, minute pulmonary meningothelial-like node may account for the pathogenesis of PPM. Macroscopically, the tumors are solitary, well circumscribed with a yellow-tan to grey cut surface. Histologically, the classical features of PPM
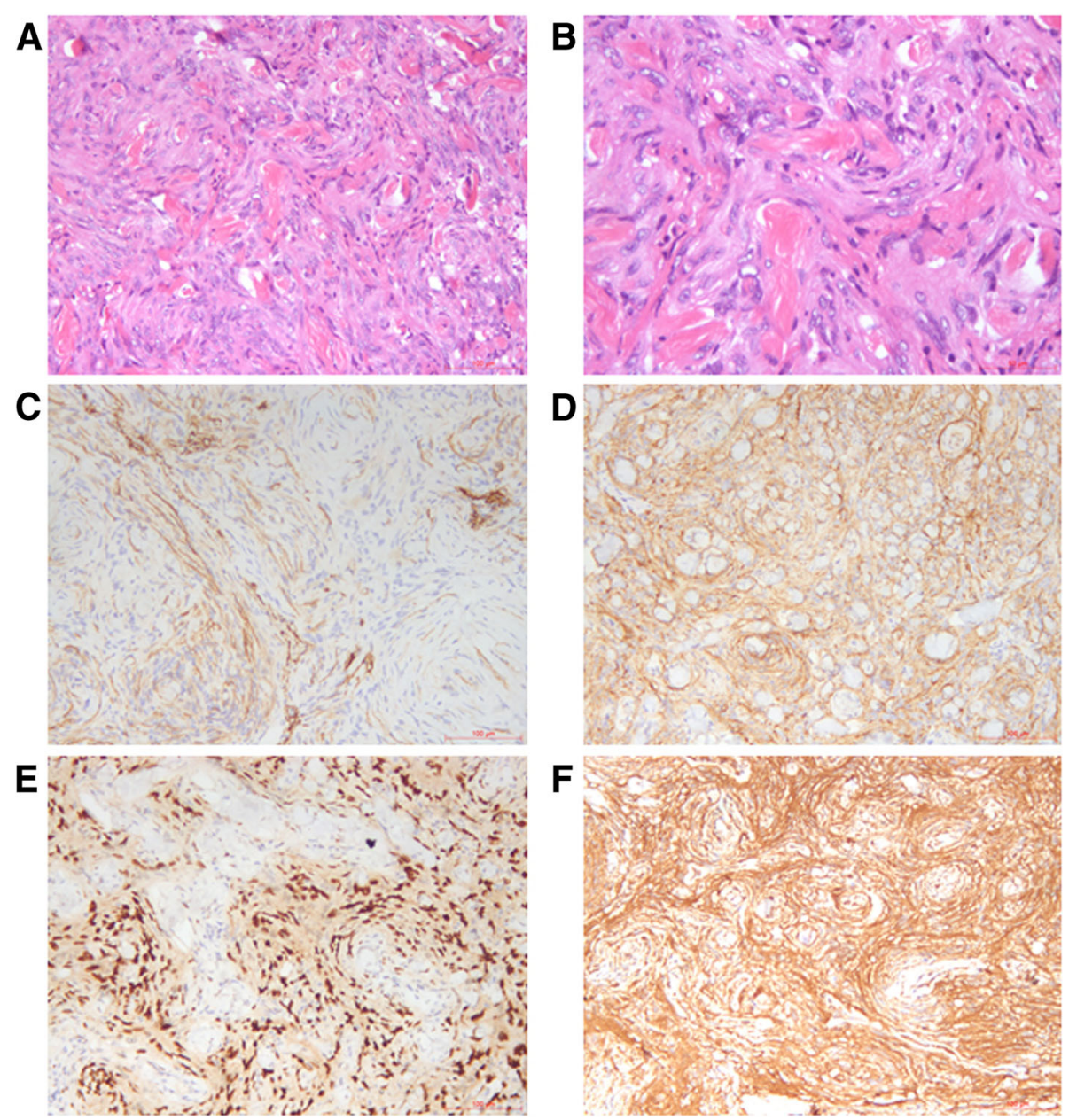

Fig. 2 Histological section of the tumor demonstrating spindle cells with a whorl pattern $(\mathbf{a}[20 x]$ and $\mathbf{b}[40 \times])$. On immunohistochemistry the tumor cells stained positive with VIM (c [20x]), EMA (d [20x]), PR (e [20x]) and CD 34 (f [20x]) 
showed whorls of spindle cells interspersed with abundant psammoma bodies. Tumor cells were positive for vimentine and EMA, and were negative for SMA, TTF-1, Chromogranin A, synaptophysin. Additionally, we found that PPM cells also expressed PR, CD34 and focally for S100 [3].

The incidence of the disease is slightly higher in women than in men, and the median age is 57 years, with a range of $18-108$ years. We report here a 65 year old female with no specific symptoms, no evidence of infection, tuberculosis, no enlargement of hilar and mediastinal lymph nodes, no lesion of extrathoracic organs. However, CT scans of our patient revealed a round-like, heterogeneous lobulated solitary pulmonary mass, possible diagnoses were tuberculoma, metastatic tumor, and benign pulmonary tumors. Previous studies indicated that most PPMs were peripheral, round-shape, well circumscribed and a homogeneous pattern on CT scans. Typical CT features of pulmonary metastases tumors were single or multiple, round, well circumscribed with smooth margin. A halo of ground-glass opacity surrounded the tumor may cause haemorrhage. Others preoperative differential diagnoses including sclerosing hemangioma, hyalinizing granuloma, intrapulmonary fibrous tumor and inflammatory pseudotumor, but the final diagnosis relies on pathological examination. Surgical resection was the curable treatment method, and the prognosis of PPM patients were excellent. Matteo and colleagues [4] summarized the surgical procedures of all 22 PPM patients with a definitive evidence of central nervous system negative for meningioma. There were 12 patients received lobectomy, nine received wedge resection and one receive pneumonectomy. Twenty patients were alive and disease free after a median follow-up time of 30 (5-96) months, which demonstrated that PPM exhibit a benign behavior. No patients had received postsurgical adjuvant therapy. It remains to be observe whether there will be recurrence after surgery.

\section{Conclusions}

PPM is an extremely rare benign tumor. The CT features of PPM can be presented as heterogeneous, lobulated mass. Expression of vimentine, EMA, PR, CD34 and S100 helps to diagnosis of PPM.

\footnotetext{
Abbreviations

CEA: Carcinoembryonic antigen; CRP: C-reaction protein; EMA: Epithelial membrane antigen; IHC: Immunohistochemical; MRI: Magnetic resonance imaging; NSE: Neuron-specific enolase; PPM: Primary pulmonary meningioma; PR: Progesterone receptor; SCC: Squamous cell carcinoma antigen

\section{Funding}

This work was supported by by the National Natural Science Foundation of China (Grant No. 81472225) (www.nsfc.gov.cn/).
}

Availability of data and materials

Please contact author for data requests.

\section{Authors' contributions}

YS conceived the report. $J$ and CZ wrote the first draft with input from all authors. All authors approved the final manuscript.

\section{Ethics approval and consent to participate}

The study protocol was approved by the Ethics Committee of the Zhongshan Hospital (Fudan University, Shanghai, China) and was conducted according to the Declaration of Helsinki.

\section{Consent for publication}

Consent for publication of this case report in its entirety was obtained from the patient.

\section{Competing interests \\ The authors declare that they have no competing interests.}

\section{Publisher's Note}

Springer Nature remains neutral with regard to jurisdictional claims in published maps and institutional affiliations.

\section{Author details}

'Department of Thoracic Surgery, Zhongshan Hospital, Fudan University, Shanghai 200032, People's Republic of China. ${ }^{2}$ Department of Pathology, Zhongshan Hospital, Fudan University, Shanghai 200032, People's Republic of China.

Received: 1 July 2018 Accepted: 24 September 2018

Published online: 01 October 2018

References

1. Huang $S$, Chen L, Mao $Y$, Tong H. Primary pulmonary meningioma: a case report. Medicine. 2017;96(19):e6474.

2. Izumi N, Nishiyama N, Iwata T, Nagano K, Tsukioka T, Hanada S, et al. Primary pulmonary meningioma presenting with hemoptysis on exertion. Ann Thorac Surg. 2009;88(2):647-8.

3. Oide T, Hiroshima K, Shibuya K, Nakatani Y. Primary pulmonary meningioma presenting as a coin lesion. Intern Med. 2017;56(15):2073-4.

4. Incarbone M, Ceresoli GL, Di Tommaso L, Cappuzzo F, Inzirillo F, Infante M, et al. Primary pulmonary meningioma: report of a case and review of the literature. Lung Cancer. 2008;62(3):401-7.

\footnotetext{
Ready to submit your research? Choose BMC and benefit from:

- fast, convenient online submission

- thorough peer review by experienced researchers in your field

- rapid publication on acceptance

- support for research data, including large and complex data types

- gold Open Access which fosters wider collaboration and increased citations

- maximum visibility for your research: over $100 \mathrm{M}$ website views per year

At BMC, research is always in progress.

Learn more biomedcentral.com/submissions
} 